\title{
Bidirectional Brush Seals - Post-Test Analysis
}

\author{
ROBERT C. HENDRICKS ${ }^{a}$,* JACK WILSON ${ }^{b}$, TOM Y. WU $^{a}$, RALPH FLOWER $^{c}$ \\ and ROBERT L. MULLEN ${ }^{\mathrm{d}}$ \\ ${ }^{a}$ National Aeronautics and Space Administration, Lewis Research Center, Cleveland, OH 44135, USA; \\ ${ }^{\mathrm{b}}$ NYMA, Inc., Brook Park, OH 44135, USA; ' Cross Manufacturing Ltd., Devizes, England, UK; \\ ${ }^{\mathrm{d}}$ Case Western Reserve University, Cleveland, OH 44106, USA
}

(Received 10 May 1998; In final form 12 June 1998)

\begin{abstract}
A post-test analysis of a set of inside-diameter/outside-diameter (ID/OD) bidirectional brush seals used in three-port wave rotor tests was undertaken to determine brush bristle and configuration wear, pullout, and rotor coating wear. The results suggest that sharp changes in the pressure profiles were not well reflected in bristle tip configuration patterns or wear. Also, positive-to-negative changes in axial pressure gradients appeared to have little effect on the backing plates. Although the brushes had similar porosities, they had very different unpacked arrays. This difference could explain the departure of experimental data from computational fluid dynamics flow predictions for well-packed arrays at higher pressure drops. The rotor wear led to "car track" scars (upper and lower wear bands) with a whipped surface between the bands. Those bands may have resulted from bristle stiffening at the fence and gap plates during alternate portions of the rotor cycle. Within the bristle response range the wear surface reflected the pressure distribution effect on bristle motion. No sacrificial metallurgical data were taken. The bristles did wear, with correspondingly more wear on the ID brush configurations than on the OD configurations; the complexity in constructing the ID brush was a factor.
\end{abstract}

Keywords: Brush seals, Wear, Porous media, Tribology, CFD, Wave rotor

\section{INTRODUCTION}

A wave rotor topping cycle can be thought of as pressure-gain combustion (Kentfield, 1995; Wilson and Paxson, 1996). A wave rotor machine uses expansion and shock waves within rotating passages on the rotor to expand or compress the working fluid, work typically done in conventional turbomachinery by an axial blade or vane or a centrifugal component. In the wave rotor machine both compression and expansion occur in the same device, and in some cases chemical reactions take place.

Sealing can be a major factor in the wave rotor machine because dynamic, small changes in volume represent significant losses. The leakage takes place into or out of a passage through the gap between the passage and the end walls of the machine. The leakage flow changes direction depending on whether the passage is at high or low pressure.

\footnotetext{
*Corresponding author. Tel.: 216-977-7507.
} 
These end-wall losses can potentially be controlled by seals, such as compliant brush seals or close selfactivating rim or leaf seals, that accommodate high surface speeds. Because brush seals could be incorporated easily into an existing three-port wave rotor at NASA Lewis Research Center (Wilson, 1997), bidirectional seals were fabricated and tested (Hendricks et al., 1997). Tests were made of wave rotor performance with and without the brush seals. In essence, the baseline configuration had no seals; the sealing interfaces were the gaps between the components. Relative to the baseline configuration, data indicated that the bidirectional brush seals enhanced wave rotor efficiency from $36 \%$ to $45 \%$ at low leakages (small rotor end-wall gap spacings) and from $15 \%$ to $33 \%$ at high leakages (larger end-wall gap spacings). Surface tribology for those tests suggested little evidence of grooving, although the bristles did wear-in and the rotor surface appeared polished.

Further post-test evaluation of the bidirectional brush seals is reported herein, providing surface morphology, such as brush bristle and configuration wear, pullout, and coating wear. The results suggest that sharp changes in the pressure profiles were not well reflected in bristle or surface wear patterns and had little effect on the backing plates. For completeness and to assist the reader, the rotor and bidirectional brush descriptions given previously (Hendricks et al., 1997) will be repeated herein.

\section{APPARATUS}

A photograph of the wave rotor test rig (Fig. 1) illustrates the nature of a three-port flow divider. A single inlet flow is separated into two outlet flows, one at higher stagnation pressure than the inlet and the other at lower stagnation pressure. The rotor itself is a cylinder with axially aligned passages on its circumference. As a passage rotates, the pressures at the ends of the passage fluctuate between the high and low pressures. The cavity surrounding the rotor will be at a pressure close to

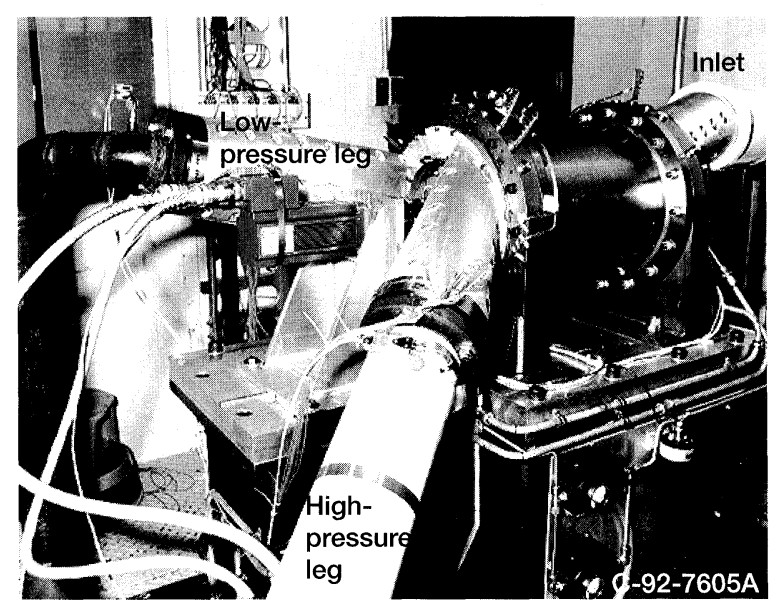

FIGURE 1 Wave rotor test rig.

the inlet pressure. Leakage will take place from a passage to the cavity when the passage is at high pressure and from the cavity to a passage when the latter is at low pressure. Thus, the seals must be capable of withstanding pressure reversals and the corresponding flow reversals.

A cross-sectional view of the rotor (Fig. 2) illustrates the cavities and the placement of the brush seals. The rotor passage represents that portion of the rotating cylinder containing the working fluid; the inner and outer cavities constitute potential leakage paths. The movable end wall establishes a gap between the unsealed rotor/stator interface and to some extent controls the cavity volumes at the sealed rotor/stator interface.

Sixty $1.37-\mathrm{cm}$-wide (0.54-in-wide) passages are spaced around the circumference of the rotor. As the rotor turns, the pressures at each end of a passage fluctuate, with the highest pressure being about three to four times the lowest pressure. The leakage may be thought of as having radial and circumferential components. Circumferential leakage is from passage to passage where the pressure differences are not large, so this leakage is believed to be less important than radial leakage. Radial leakage is from a high-pressure passage into the cavity and then from the cavity back into a lowpressure passage. By blocking the path from the 


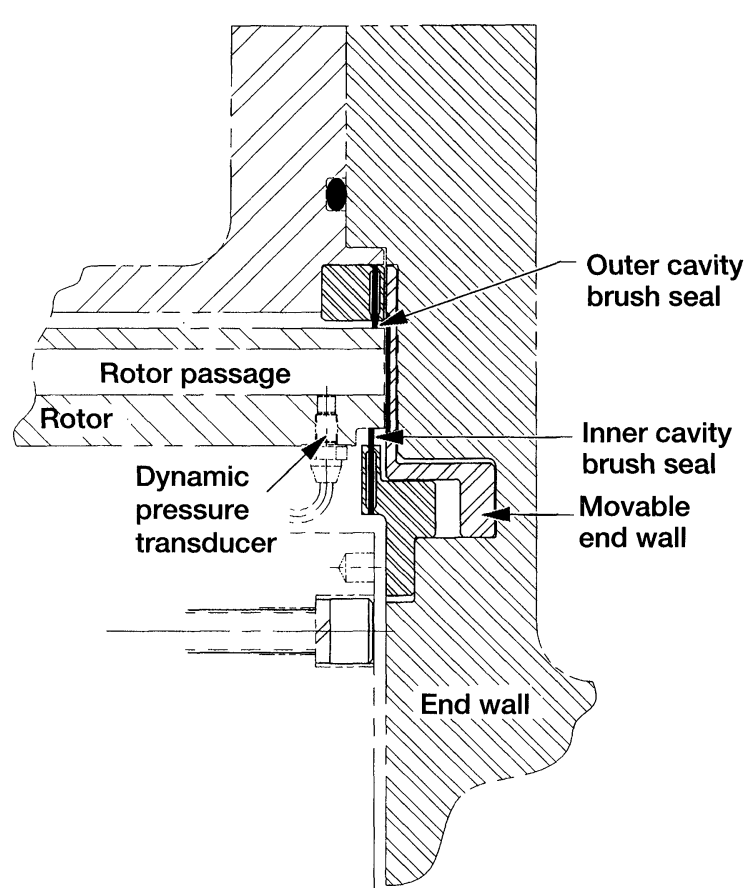

FIGURE 2 Rotor cross section.

passages into the cavity, brush seals can reduce radial leakage.

\section{BRUSH SEAL REQUIREMENTS}

The wave rotor represents an unusual set of operating conditions for a brush seal. In addition to the usual compliance and sealing requirements the brush must do the following:

1. Seal bidirectional flows;

2. Seal pressures to $\pm 276 \mathrm{kPa}$ ( $\pm 40 \mathrm{psi}$ );

3. Withstand surface speeds to $152 \mathrm{~m} / \mathrm{s}(500 \mathrm{ft} / \mathrm{s})$ at temperatures below $177^{\circ} \mathrm{C}\left(350^{\circ} \mathrm{F}\right)$;

4. Seal the interface at both the inside and outside diameters;

5. Seal both ends of the wave rotor (i.e., matching pairs are required) and

6. Retrofit into the existing equipment with minimum modifications.
The shielded design (Hendricks et al., 1990; 1992) can be modified to provide sealing in both directions, provided that a gap is introduced between the side plates and the bristles. Figure 3 shows crosssectional views of the OD and ID seals. The brush was otherwise of standard Cross Mfg. Co. construction. The bristles were 0.071 -mm-diameter $(0.0028$ in-diameter) Haynes 25 (AMS 579628 ) at $40^{\circ}-50^{\circ}$ angles to the interface and inclined in the direction of rotation with suitable antirotation pins to prevent seal rotation. The rotor seal radii after testing were nominally $140.2 \mathrm{~mm}$ (5.518 in) (inner) and $162.1 \mathrm{~mm}$ (6.380 in) (outer). In each case $0.25-\mathrm{mm}(10-\mathrm{mil})$ radial interference was built into the as-manufactured seal.

The rubbing interfaces on the rotor were Proxair LC-1H (Union Carbide) chromium carbide coated to $0.15-0.25 \mathrm{~mm}(0.006-0.010$ in) thick.

\section{BRUSH SEAL WEAR-IN}

The brush seals were installed by rotating them into position, and suitable static O-rings provided the necessary static seals. The rotor was torqued by hand to set the bristles. Then, in a set of break-in runs the speed was gradually increased to $4000 \mathrm{rpm}$ in 200-rpm increments over a 12.5-h break-in period. After the bristles were set and rubbed into place, a borescope examination of the bristles revealed the characteristic powder debris in flow stagnation regions, the remainder of the debris being swept away with the flow. Some bristles strayed beyond the pack, with those of the inner seal being most susceptible.

\section{OPERATIONS}

After break-in the system was operated for a total of $7.5 \mathrm{~h}$ at $7400 \mathrm{rpm}$. The rotor average temperature was approximately the inlet temperature, $322 \mathrm{~K}$ $\left(580^{\circ} \mathrm{R}\right)$ with hot gas temperatures to $402 \mathrm{~K}\left(724^{\circ} \mathrm{R}\right)$ and cold-side temperatures to $284 \mathrm{~K}\left(511^{\circ} \mathrm{R}\right)$. 

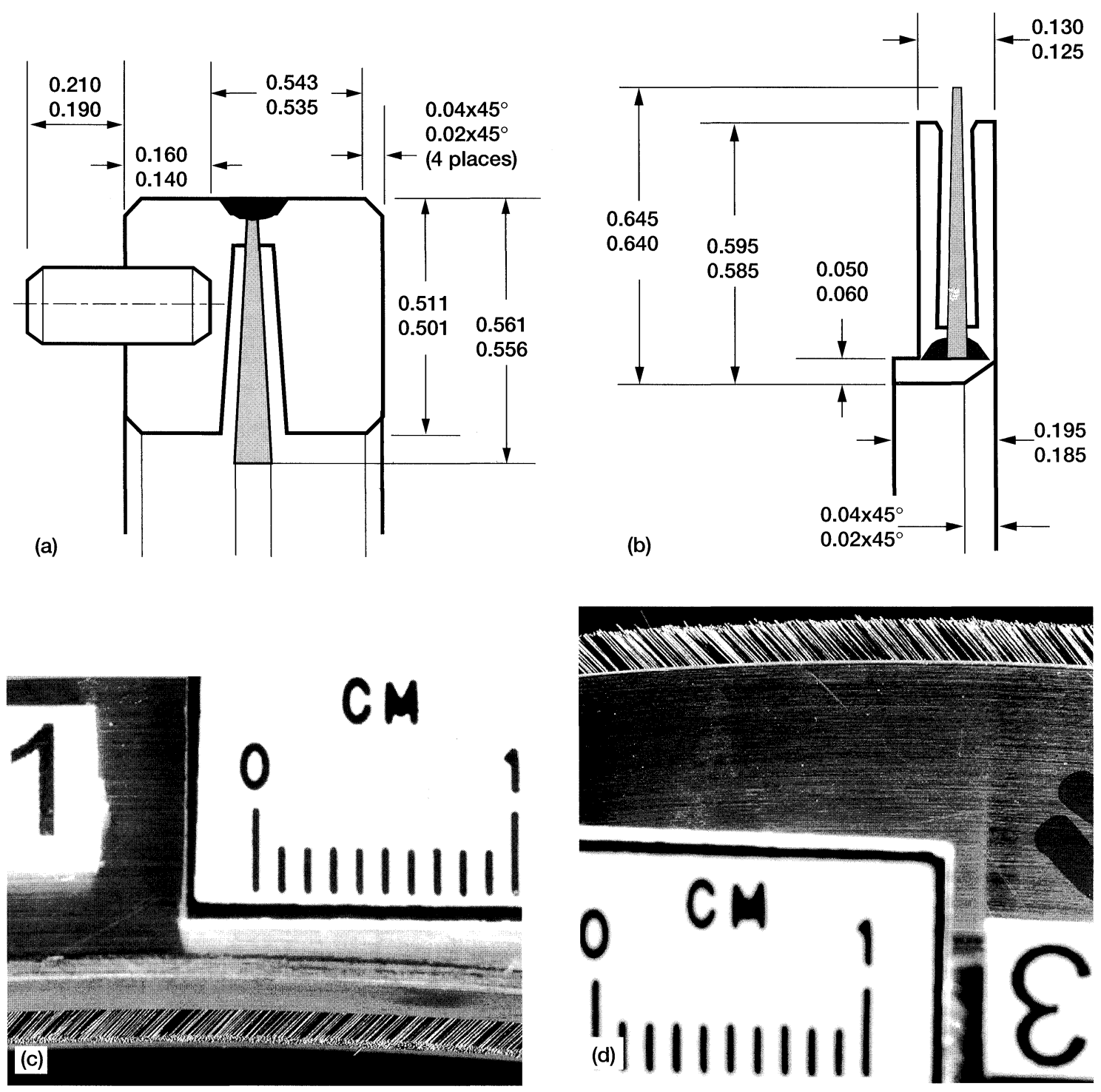

FIGURE 3 Details of seal cross sections and photographs of brush seals taken after testing: (a) outer brush seal cross section; (b) inner brush seal cross section; (c) OD seal bristles and side plate fence and (d) ID seal bristle and side plate fence

\section{COMMENTS ON POROSITY DETERMINATION}

For an ideal configuration of circular or elliptical cylinders, $g_{1}=g_{2}=g$, the porosity $\varepsilon$ becomes

$$
\varepsilon=1-\frac{\pi}{2 \sqrt{3}(1+g /(2 a))(1+g /(2 b))},
$$

where $g$ denotes gap; $2 a$ indicates the major axis; and $2 b$, the minor axis (Fig. 4). The bristle-rotor interface, for most brush seals, represents a plane of small curvature. At this interface leakage occurs and is compounded by flows along the bristles.

When estimating either the nonideal or unpacked porosity from a photograph, the number of bristles $N_{\mathrm{t}}$ is counted for a specified area $A_{\mathrm{t}}$, of length $L$, 


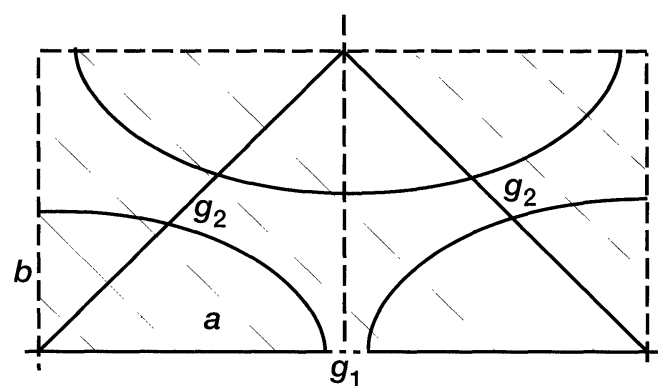

FIGURE 4 Ideal packing of cylinders (brush-bristle geometry).

and width $w$ expressed in terms of bristle diameters. The area occupied by the bristles $A_{\mathrm{s}}$ is elliptical and expressed as the ratio of the cylindrical bristle area to $\cos (\theta+\phi)$, where $(\theta+\phi)$ represents the interface angle with respect to the brush, $\theta$ denotes the angle from bristle attachment, and $\phi$ denotes the angle from the rotor centerline. The unpacked porosity becomes

$$
\varepsilon=1-\frac{A_{\mathrm{s}}}{A_{\mathrm{t}}}=1-\frac{N_{\mathrm{t}} \pi d^{2}}{4 w L \cos (\theta+\phi)} .
$$

If, however, the packing is ideal and the gap $g$ is known, the porosity is given by Eq. (1). Conversely, if the porosity is known and the ideal gap $g$ is unknown, $g$ can be estimated by equating Eqs. (1) and (2) and solving for $g$. Further, if the brush thickness $\langle t\rangle$ and the number of bristle rows $N_{x}$ are known for an ideal spacing of $d+\varepsilon_{0}$, where gap $g \equiv \varepsilon_{0}$ and $d$ is bristle diameter,

$$
\varepsilon_{0}=\frac{2\langle t\rangle}{\sqrt{3} N_{x}}-d
$$

and from Eq. (1)

$$
\varepsilon=1-\frac{\pi}{2 \sqrt{3}\left(1+\varepsilon_{0} / d\right)^{2}} .
$$

Due to the complex way a brush seal is constructed, brush porosity is strongly threedimensional and yet is most often treated as an averaged two-dimensional property. For the OD brush the bristle pack thickness decreases as the radius increases. Essentially, the opposite is true for the ID brush. In either brush the bristles are interlayered to account for differences in arc length at the clamping radius and the interface; the bristle lay angles also differ.

Variations in brush thickness are introduced into the correlation model (Braun et al., 1990; Hendricks et al., 1992; 1997) for the ideally spaced brush. The model requires the thicknesses at the interface, at the fence, and at the clamp points in order to characterize the brush. An average brush thickness $\langle t\rangle$ was assumed for predicting both porosity and pressure drop.

Bird et al. (1960) define the specific surface $A_{\mathrm{v}}$ such that the mean particle diameter, $D_{\mathrm{p}}$, is the diameter of a sphere:

$$
A_{\mathrm{v}}=\frac{\text { Total particle surface }}{\text { Volume of particles }}=\frac{4 \pi r^{2}}{4 / 3 \pi r^{3}}=\frac{3}{r}=\frac{6}{D_{\mathrm{p}}} .
$$

For the case of circular-cylinders,

$$
A_{\mathrm{v}}=\frac{2 \pi r L}{\pi r^{2} L}=\frac{4}{d} \equiv \frac{6}{D_{\mathrm{p}}} .
$$

For the case of elliptical-cylinders,

$$
\begin{aligned}
A_{\mathrm{v}} & =4 a L \int_{0}^{\pi / 2} \sqrt{1-k^{2} \sin ^{2} x} \mathrm{~d} x /(\pi a b L), \\
& =\frac{\pi(a+b)}{4}\left[3(1+\lambda)+\frac{1}{(1-\lambda)}\right] /(\pi a b), \\
& =(1+\cos \psi)\left[3(1+\lambda)+\frac{1}{(1-\lambda)}\right] /(4 b),
\end{aligned}
$$

where

$$
\begin{gathered}
k^{2}=1-(b / a)^{2} ; \\
\lambda=\left[\frac{a-b}{2(a+b)}\right]^{2}=\left[\frac{1-\cos \psi}{2(1+\cos \psi)}\right]^{2} ; \\
2 a=d / \cos (\psi) ; \quad 2 b=d ; \quad \psi=(\theta+\phi) .
\end{gathered}
$$


Also, $A_{\mathrm{v}}$ may be approximated as:

$$
\begin{aligned}
A_{\mathrm{v} 1} & =(2 \pi a L / \sqrt{2}) \sqrt{\left.1+(b / a)^{2}\right)} /(\pi a b L) \\
& =\frac{\sqrt{2}}{b} \sqrt{1+\cos ^{2} \psi} .
\end{aligned}
$$

The values of specific surface and hydraulic fiber (particle) diameters for various angles $(\psi)$ becomes:

\begin{tabular}{lcclcc}
\hline $\begin{array}{l}\text { Angle } \\
\text { (degree) }\end{array}$ & \multicolumn{2}{c}{$\begin{array}{c}\text { Specific } \\
\text { surface }\end{array}$} & & \multicolumn{2}{c}{$\begin{array}{c}\text { Hydraulic fiber } \\
\text { diameter }\end{array}$} \\
\cline { 2 - 3 } \cline { 6 - 7 }$\psi$ & $A_{\mathrm{v}} * d$ & $A_{\mathrm{v} 1} * d$ & & $D_{\mathrm{p}} / d$ & $D_{\mathrm{p} 1} / d$ \\
\hline 55 & 3.20520 & 3.26066 & & 1.87196 & 1.84012 \\
45 & 3.43938 & 3.46410 & & 1.74450 & 1.73205 \\
35 & 3.64738 & 3.65624 & & 1.64505 & 1.64103 \\
25 & 3.81492 & 3.81772 & & 1.57277 & 1.57183 \\
15 & 3.93215 & 3.93244 & & 1.52588 & 1.52577 \\
0 & 4.00000 & 4.00000 & & 1.50000 & 1.50000 \\
\hline
\end{tabular}

The hydraulic radius is expressed in terms of porosity $(\varepsilon)$ and specific surface $\left(A_{\mathrm{v}}\right)$,

$$
R_{\mathrm{h}} \equiv \frac{\varepsilon}{a_{0}} \equiv \frac{\varepsilon}{A_{\mathrm{v}}(1-\varepsilon)} \equiv \frac{D_{\mathrm{p}} \varepsilon}{6(1-\varepsilon)},
$$

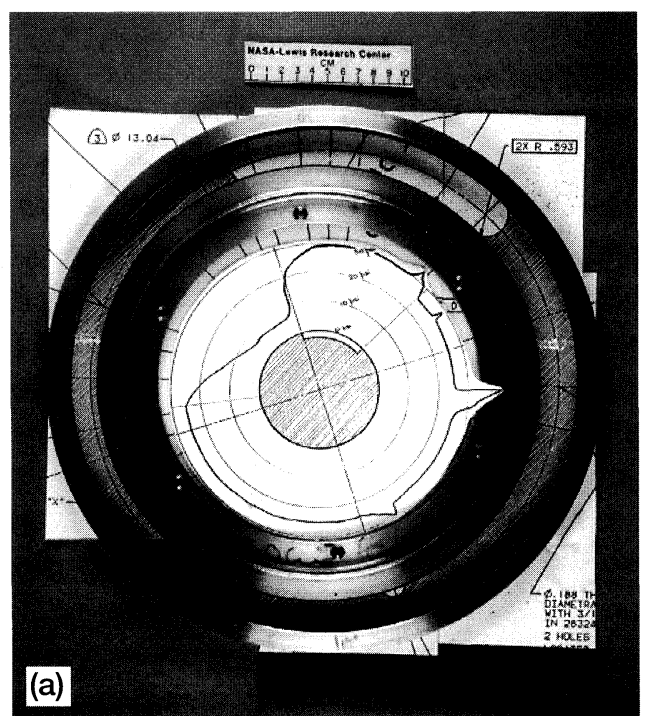

where $D_{\mathrm{p}}$ is mean particle diameter required for the bulk flow model, Hendricks et al. (1992), and $D_{\mathrm{p} 1}$ is the approximate value based on $A_{\mathrm{v} 1}$.

\section{POST-TEST SEAL ANALYSIS}

\section{Brush Pressure Profiles}

Figure 5 represents the inlet and outlet seal configurations for the wave rotor machine. The ID and OD brush seals are overlayed on a drawing of the wave rotor configuration with the associated pressure profiles to simulate the brush pressure loading. Although the 60 rotor passages rotating at $7500 \mathrm{rpm}$ provided rapidly changing pressure in the passages, the pressure profiles were steady in the laboratory reference frame. The pressure peaks and reversals with respect to the mean were substantial, forcing the bristles to flip-flop axially, at fixed circumferential positions, as the passage rotated through a cycle (Fig. 6). Consequently, one would expect to witness some changes in the brush bristle patterns in the regions of rapid pressure changes. However, bristle wear and packing abnormalities appeared to be dispersed over the entire circumference of the brush and showed no evidence of the local pressure changes on bristle packing or wear.

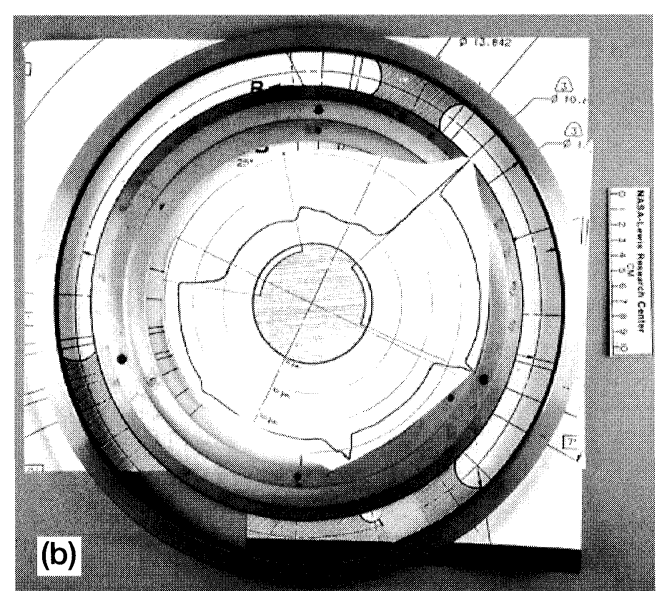

FIGURE 5 Simulation overlay of wave rotor end wall with no-seal pressure distribution: (a) inlet and (b) outlet. 
Nevertheless, the rotor surface was affected as discussed in the section Surface Tribology.

\section{Optical Inspection of OD Brush}

Figure 7 is a typical representation of the OD brush seal's bristle tip configuration. Although these photographs are typical of the unpacked brush, some regions show a higher degree of bristle void. For example, in counting the bristle tips in Fig. 7(a) over a circumferential distance of about $4.67 \mathrm{~mm}$ (1.84 in) and an unpacked-brush thickness $\langle t\rangle$ of about $1.19 \mathrm{~mm}(0.468 \mathrm{in})$, three separate counts gave $N_{\mathrm{t}}$ of 240,300 , and 370 , depending on where on the brush circumference the count was taken. The manufacturer estimates $N_{\mathrm{t}}=459$. The number of bristle rows was estimated at $N_{x}=11$. The average
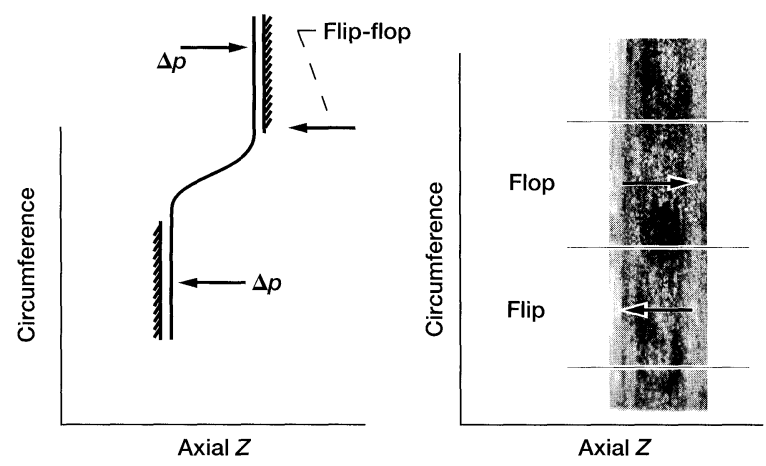

FIGURE 6 Bristle "flip-flop" with passage rotation.

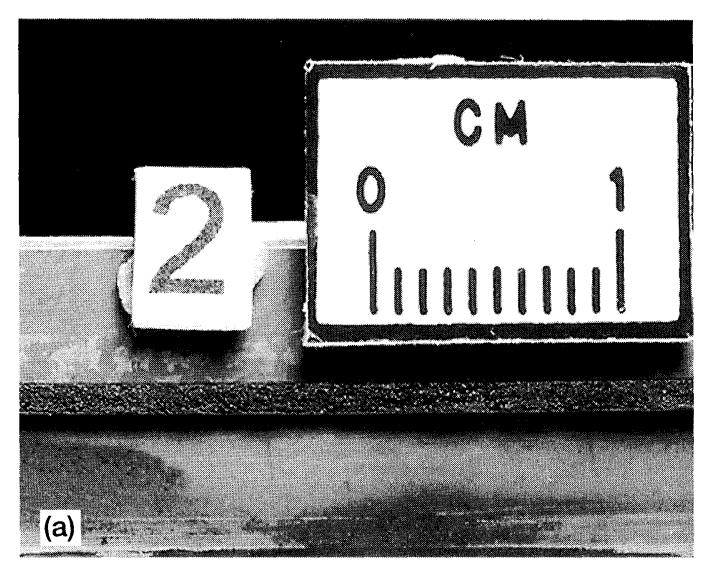

bristle diameter was $0.071 \mathrm{~mm}$ (0.0028 in), and the average interface angle $(\theta+\phi)$ was $46^{\circ}$. The porosity adapted from Eq. (2), where $V_{\mathrm{S}}$ denotes bristle volume and $V_{\mathrm{t}}$ denotes total volume,

$$
\varepsilon=\frac{V_{\mathrm{s}}}{V_{\mathrm{t}}}=1-\frac{N_{\mathrm{t}} \pi\left(d^{2} / 4\right)}{1.19 \times 4.57 \cos (\theta+\phi)}
$$

became $0.74,0.68$, and 0.60 for the three counts, respectively, and was 0.5 as per the manufacturer. In terms of the number of rows of bristles $N_{x}$ and assuming an ideal packing (equilateral triangles spaced at $\left.\left(d+\varepsilon_{0}\right)\right)$, Eqs. (3) and (1a) provide

$$
\varepsilon_{0}=\frac{2\langle t\rangle}{\sqrt{3} N_{x}}-d=\frac{2 \times 1.2}{1.732 \times 11}-0.71=\frac{3 d}{4} .
$$

This gap is unusally large, yet representative of this particular portion of the unpacked brush interface. The porosity becomes

$$
\begin{aligned}
\varepsilon & =1-\frac{\pi}{2 \sqrt{3}\left(1+\varepsilon_{0} / d\right)^{2}} \\
& =1-\frac{\pi}{2 \times 1.732 \times(1+3 / 4)^{2}}=0.7
\end{aligned}
$$

which is more in agreement with the 0.74 and 0.68 bristle count porosities than with the manufacturer's value of 0.5 . Higher magnification and more

FIGURE 7 Unpacked OD brush seal: (a) overview and (b) $50 \times$. 
reliable bristle counts are required over the entire interface.

Although not a digitized representation, Fig. (8) nominally represents the nonuniformity of the unpacked OD brush similar to that shown in Fig. 7(b). Counting the bristles in each row $N_{x}$ in Fig. 7(b) gave $N_{\mathrm{t}}=140$. Counting the bristles over a fixed area, $N_{\mathrm{t}}=156$ bristles. For an area of $70 \mathrm{~mm}$ by $40 \mathrm{~mm}$ and a scale factor of $3 \mathrm{~mm}=d$, with other parameters essentially the same (e.g., $\theta+\phi=46^{\circ}$ ) and $\left\langle N_{\mathrm{t}}\right\rangle=148$, the unpacked porosity became

$$
\varepsilon_{2 \mathrm{D} \text { interface }}=1-\frac{148 \pi d^{2} / 4}{\cos (\theta+\phi)\left[70 \times 40(d / 3)^{2}\right]}=0.46
$$

with an estimated packed porosity $0.19<\varepsilon_{\text {packed }}$ $<0.28$.
The packed brush thickness and associated porosities were estimated from post-test photographs (e.g., Fig. 7(b) at $50 \times$ ), and by measuring the axial thickness reduction ratio of the packed to unpacked brush $\left[\frac{2}{3}\langle t\rangle\right.$ nonpack $]<[\langle t\rangle$ packed $]<$ $\left[\frac{3}{4}\langle t\rangle\right.$ nonpack]. A note of caution; if one assumes ideal equilateral bristle packing configuration and applies this ratio to all sides of the ideal packing triangle, i.e., packed axially and cicumferentially versus axial packing alone, unrealistic results may occur due to very small differences in void.

Figure 9 shows a bristle tip core with a surface resembling a cast-iron fracture. The core is rough with pits and bumps. No metallurgical tests were performed because the brush has been reserved for further flow testing. Only marginally visible are grooves and ridges scratched across the tips in

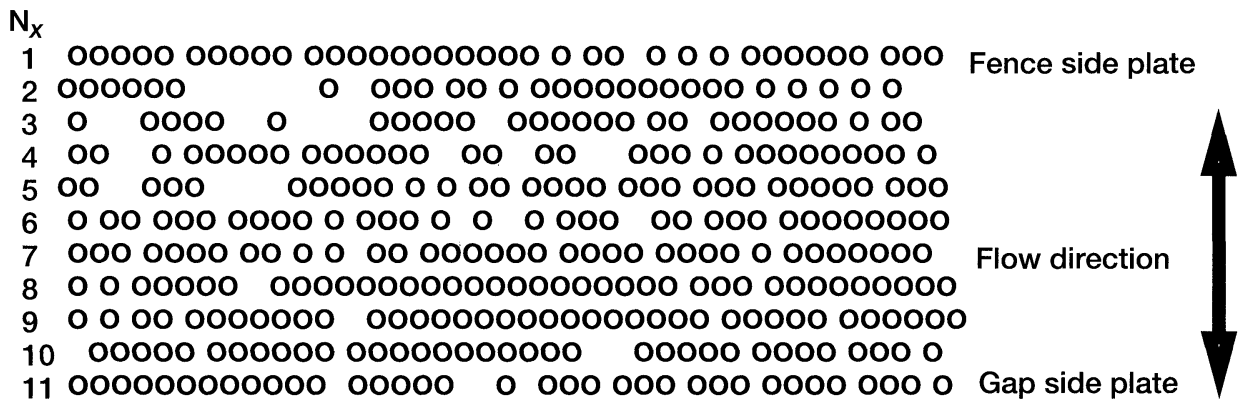

FIGURE 8 Simulation of bidirectional OD brush seal bristle tips.

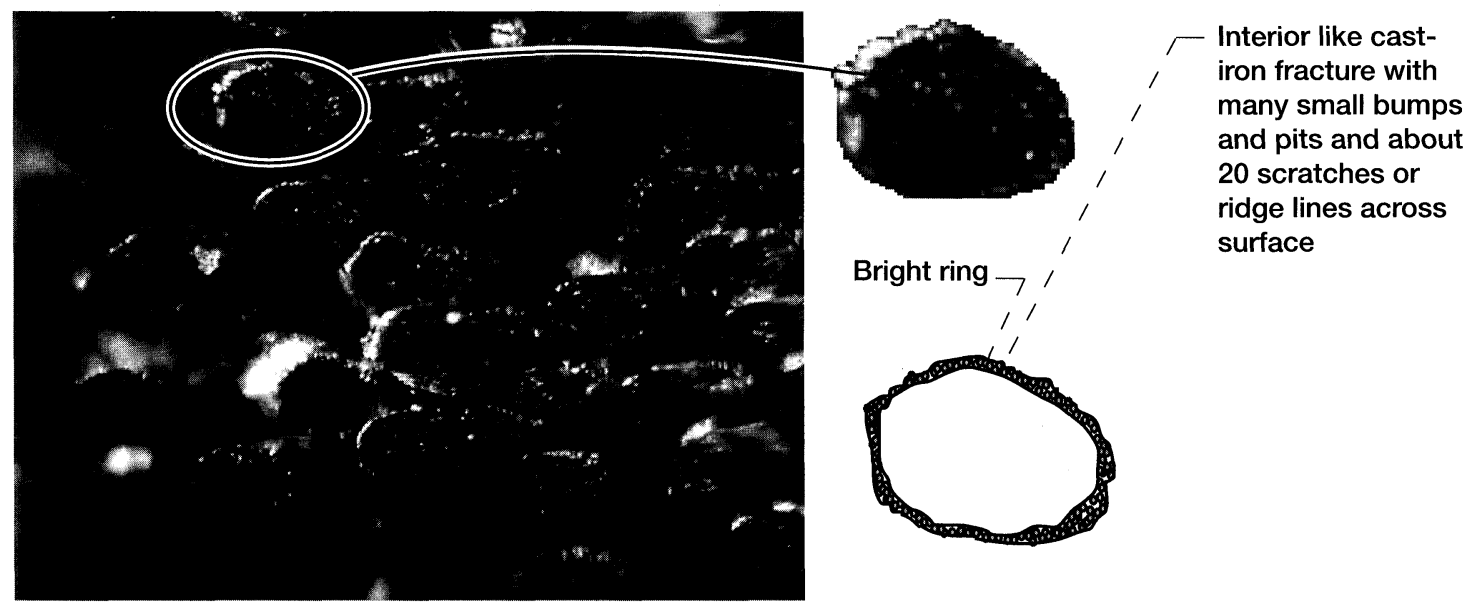

FIGURE 9 OD brush bristle tips $128 \times$ and observed grooving. 
the direction of rotation. Typically, each tip will have 15-20 visible scars with a bristle diameter of $0.071 \mathrm{~mm}(0.0028 \mathrm{in})$. The scars are perhaps $4 \mu \mathrm{m}$ (160 $\mu \mathrm{in})$ wide, and transfer material is scattered over the surface, as represented in the sketch in Fig. 9.

Small particulate matter that looked like dust was found on the rotor outlet. This "dust" may be related to material loss or transfer at the interface. The seal may have operated line to line at the later stages of testing.

Figure 10 illustrates bristle pullout or significant subsurface displacement of a bristle or a set of bristles that dislodged the brush at the fence plate. The surrounding bristles are even and show no distress. Part of the bristle bunching may be due to in-pack bending, twisting, or shearing of bristles.

\section{Optical Inspection of ID Brush}

Figure 11 illustrates the disheveled nature of the bristle interface with more evidence of bristle pullout or bunching. There are several reasons for this:

1. The brush seals were set into position with nearly blind access.

2. The installed measured diametral interference was more than $1 \mathrm{~mm}$ ( 40 mils).

3. Brush construction is much more complex in the ID configuration than in the OD configuration. The bristle pack thickness for an ID seal has to increase as the radius decreases (i.e., thickest at pinch radius), whereas just the opposite is the case for an OD seal, Fig. 3(b).

4. Control of rotor concentricity, surface finish, and coating is much more difficult in the ID configuration than in the OD configuration.

5. Figure 11 also illustrates the erratic bristle lengths (the "chewed" appearance) and the potential for dislodging and pullouts.

Figure 12 was taken to determine the unpacked porosity. For $N_{\mathrm{t}}=250$ with a scale factor of $3 \mathrm{~mm}$ $(0.12 \mathrm{in})=d$, an area of $103 \mathrm{~mm} \times 50 \mathrm{~mm}(4.06 \mathrm{in} \times$ $1.97 \mathrm{in}$ ), and a bristle angle at the interface of

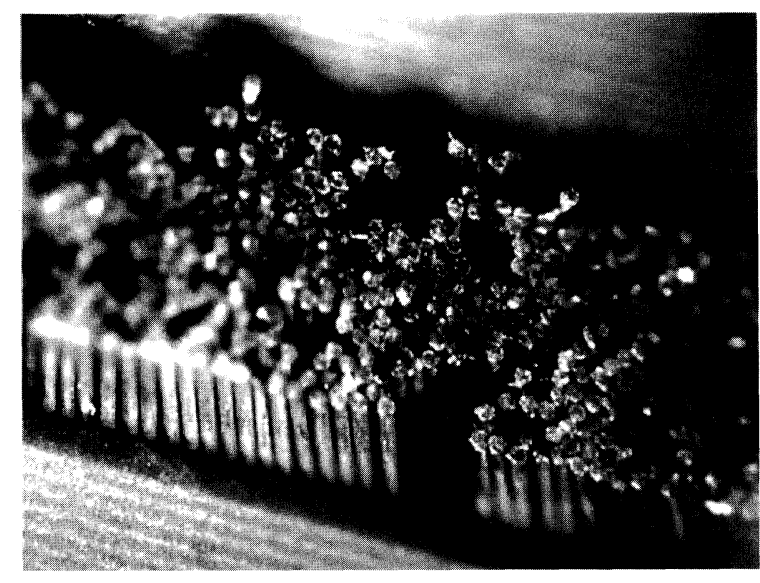

FIGURE 10 OD brush bristle pullout or subsurface displacement.

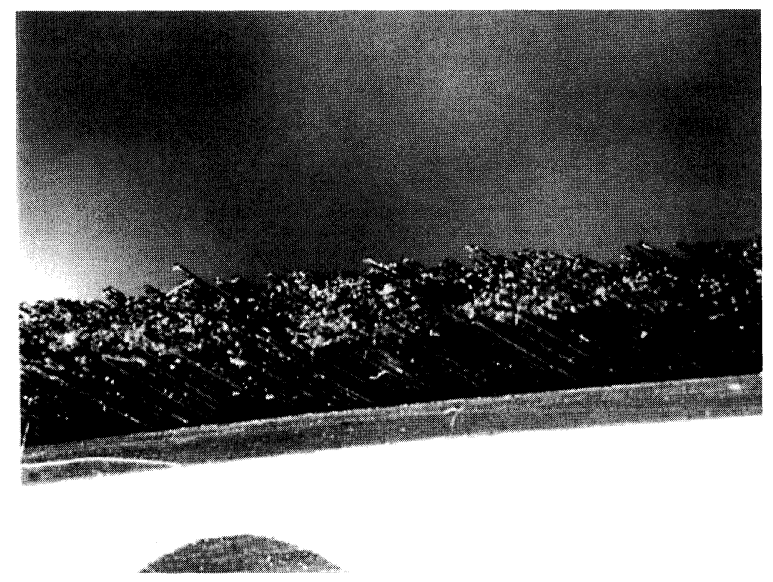

FIGURE 11 Disheveled nature of ID brush bristle interface.

$\langle\theta+\phi\rangle=48^{\circ}$, the unpacked porosity becomes, Eq. (2),

$$
\varepsilon=1-\frac{250 \pi d^{2} / 4}{\cos (48)\left[103 \times 50(d / 3)^{2}\right]}=0.48
$$

with an estimated packed porosity of $0.22<$ $\varepsilon_{\text {packed }}<0.31$. The number of bristles per unit circumference for $d_{\text {bristle }}=0.071 \mathrm{~mm}(0.028 \mathrm{in})$ is

$$
\begin{aligned}
N_{\mathrm{t}} & =\frac{250}{103(0.071 / 3)} \\
& =103 / \mathrm{mm}(2616 / \text { in }) \text { of circumference }
\end{aligned}
$$




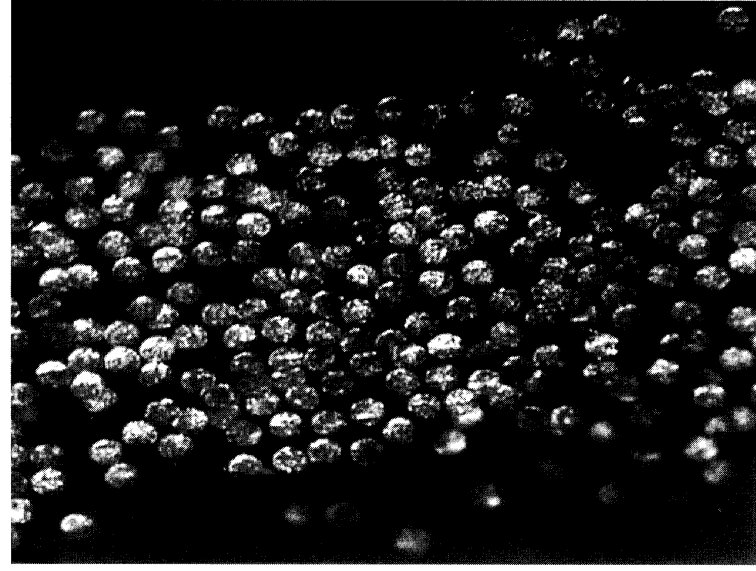

FIGURE 12 Assessment of bristle count for ID brush seal at $50 \times$. which is in good agreement with the manufacturer's value of

$$
N_{\mathrm{t}}=98 / \mathrm{mm}(2490 / \text { in }) \text { of circumference. }
$$

The row counts were difficult to assess. Figure 12 shows that, potentially, the number of rows $N_{x}=$ 14 and illustrates regions of void and bristle "bunching" (see also Fig. 11).

As cited in the OD brush observations, the level of optical detail observed simply cannot be captured by the imaging system, at any magnification. Yet it is the best available. Consequently, observed surface details can be described that are not evident in Fig. 13. For example, variations in
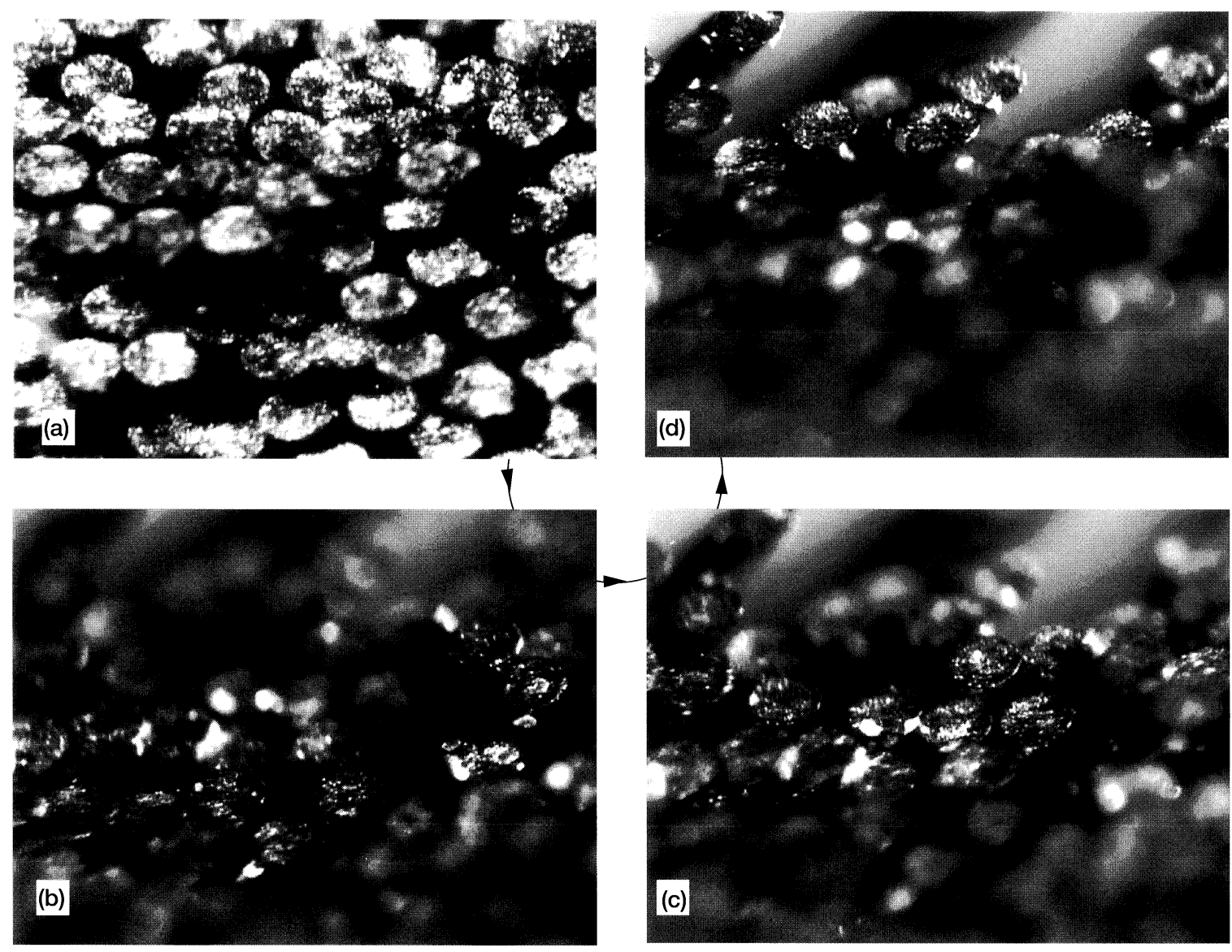

FIGURE 13 Bristle tip observations at 128x: (a) variation in bristle length at radius $r$; (b) focal plane at radius $\mathrm{d} r$; (c) focal plane at $r-2 \mathrm{~d} r$. and (d) focal plane at $r-3 \mathrm{~d} r$. 
bristle length of up to 10 bristle diameters are commonplace within the brush pack (Fig. 13(a)). However, the photographic resolution has limited depth of field, and some tips are out of focus. To provide some concept of bristle length variation, photographs (Fig. 13(b)-(d)) were taken at three focal planes at progressively smaller radii. These figures partially capture the changes in bristle length by using the out-of-focus bristles to provide a sense of depth.

\section{Effects on Future Computational Effort}

Computational fluid dynamic (CFD) calculations of ideal arrays with porosities simulating those of brush seals show few areas for recirculation or transition to turbulence (Kudriavtsev et al., 1997; Athavale et al., 1995). The Reynolds numbers are just too small. However, several types of flow pattern emerge in fabricated bristle arrays (Braun et al., 1990), and photographs of the unpacked outside seal at $50 \times$ and $64 \times$ (not shown) revealed several void areas that had little geometric similarity yet had nearly the same unpacked porosity. It is also known, from the CFD calculations and experimental data near wall boundaries, that the Reynolds numbers become significantly higher because of the increased leakage and that recirculation patterns appear (Hendricks et al., 1992; Braun et al., 1990). Similarly, the propensity for rivering and vortical flows is enhanced for ill-ordered arrays. One could also assume that the irregularity of these arrays increases with bristle motion under increasing pressure drop, contributing to a "choked" flow effect at sufficiently high pressure ratios. These effects may explain why brush seal data depart from CFD results for ordered arrays.

Experimental brush seal data (e.g., Carlile et al., 1992) tend to follow the Ergun relation (Ergun, 1952), which is a linear sum of the Blake-Kozeny and Burke-Plummer equations for laminar and turbulent flows in porous media (Bird et al., 1960). However, although the CFD results for regular arrays of cylinders tend to be laminar with no tendency toward turbulence or vortical flows, these features may show up when very fine computational grids are used. The most likely reasons are sensitivity to small perturbations in the array and displacements due to pressure loadings. With such fine details required, the computations become expensive.

\section{Surface Tribology}

Although the bristles wore significantly and some tufts were disheveled to the point of permitting rivering and vortical patterns with enhanced radial flows, neither set of brushes appeared to deteriorate further with time. However, the break-in time was $12.5 \mathrm{~h}$ with a total time of $19 \mathrm{~h}$ and $54 \mathrm{~min}$, not thousands of hours as would be required for engine operations. This testing was at break-in nominal radial interferences of 0.15 and $0.23 \mathrm{~mm}$ (6 and 9 mils) for the OD and ID brush seals, respectively.

Attempts to quantify the surface wear were unsuccessful. Surface measurements, however, showed that the chromium carbide $(\mathrm{CrC})$ interface coating wore less than $0.025 \mathrm{~mm}$ ( $0.001 \mathrm{in})$ on all four rotor interfaces. Optically, interface polishing or burnishing could be readily observed (Fig. 14(a) and (b)). A closer examination of the tracks revealed dark bands and "skipping," or changes in hardness, which may represent either tool marks of the parent machining operation or changes in the $\mathrm{CrC}$ coating. Banded wear scars and marks (Fig. 14(c) and (d)) extended beyond the brush wear path, implying a preconditioning of the rotor surface by machining. Figure 14(c) and (d) also shows surface "spottiness," which may be related to bristle wear. Perhaps the spots were caused by bristle bunching combined with a fluttering motion during the lightly loaded portion of the cycle, a hard rub, or both.

Noting the circumferential orderly nature of the bristles near the fence (Figs. 7 and 10) and then over-laying Fig. 7(a) onto Fig. 14(c) and recalling the pressure profiles (Fig. 5), the width of the dark bands (or "car tracks") within the wear scar appear to be the packed thickness of the bidirectional brush seal. The distinctness of the upper darkened wear 

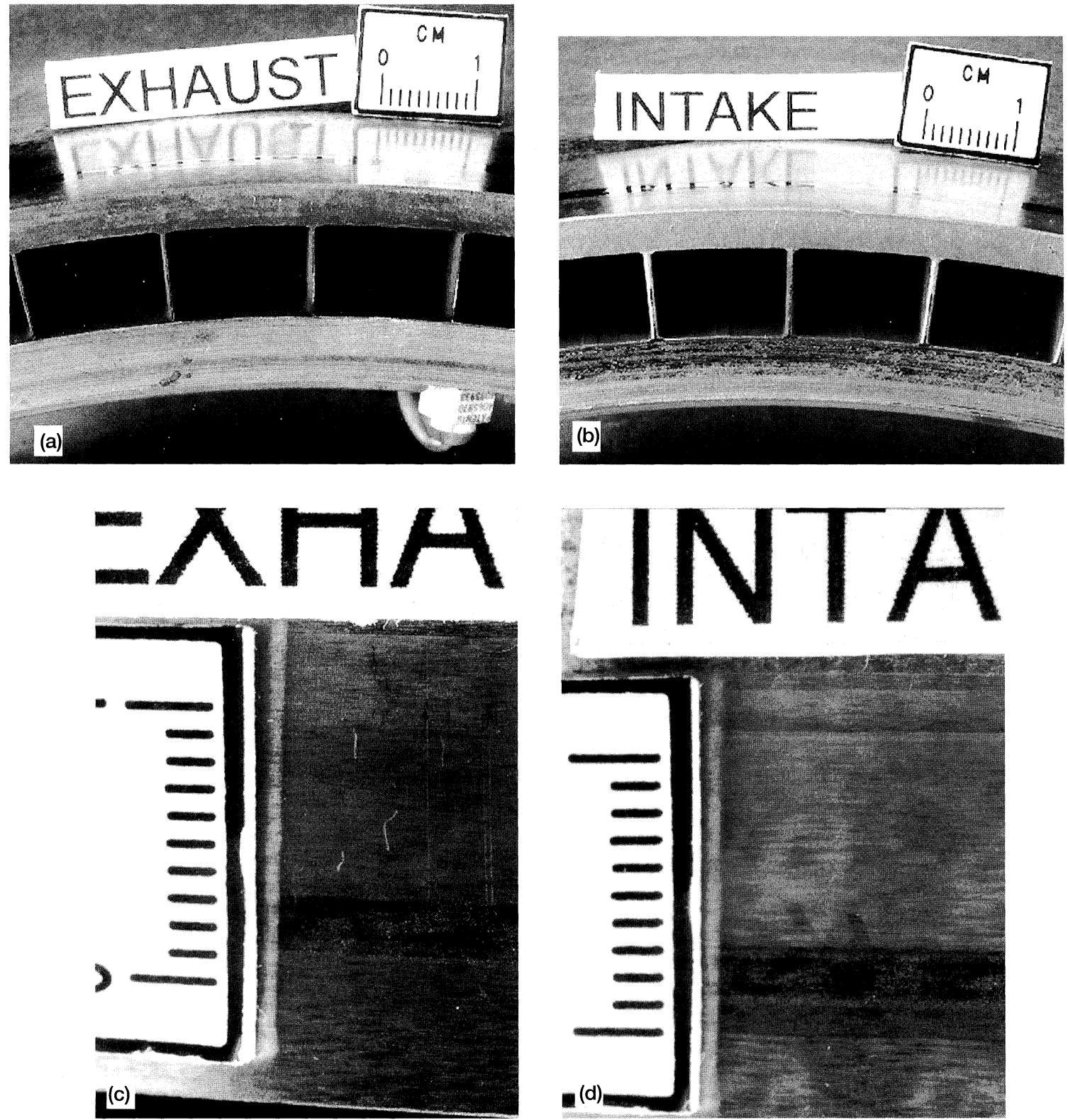

FIGURE 14 OD seal wear tracks: (a) outlet side; (b) inlet side; (c) closeup, outlet side and (d) closeup, inlet side.

scar band in Fig. 14(c) then could result from bristle stiffening near the fence plate during one portion of the rotor cycle. The lower darkened wear scar band could result from bristle stiffening against the gap plate during other portions of the rotor cycle. The lack of distinctness of the lower band may be due to enhanced bristle flexure at the gap plate during operation. The spotted nature of the wear track between the bands may have been caused by bristle flutter due to load perturbations during the lightly loaded portion of the cycle. The whipped appearance of the surface may then be caused by transverse bristle motion due to sharp pressure changes over the rotor cycle. The broadening of the lower 
band can also be attributed to bristle spreading at the rotor interface during seal installation and subsequent wear-in. The ID brush seal surface showed similar patterns, which are difficult to capture photographically.

These results infer that the wear surface reflects the axial pressure distribution applied to the bristles (see Figs. 5 and 6). If the bristles do follow the pressure loading, they are flip-flopped at about the rotor-passage passing frequency (i.e., they perform a major flip toward the fence plate at the opening of the high-pressure port and a major flop toward the gap plate at the opening of the low-pressure port during a single rotor-passage rotation). However, at $120^{\circ}$ from the opening of the high-pressure port they again flip toward the fence plate. During the lightly loaded portion of the cycle the bristles are perturbed (e.g., $60^{\circ}, 185^{\circ}$, etc.) and could be flipflopping in a fashion similar to flutter. These comments are nearly consistent with the potentially two to three prominent spacings in one passage width in the wear scars (Fig. 14). No sacrificial metallurgical examinations have been performed on either the brushes or the rotor. Thus, one can only conclude that the bristles wore significantly and that the rotor coating showed car tracking but little distress other than local burnish tracks and a high polish.

\section{SUMMARY}

A set of ID/OD brush seals capable of bidirectionally restricting flows have been successfully fabricated and tested. These brush seals have extended side plates with sufficient gap to permit compliance. Tests were run on a three-port wave rotor with the baseline (gap control only) and brush seal configurations in which the end-wall gaps were varied and the wave rotor efficiencies were measured.

Post-test optical inspection of the bilateral brush seals revealed nonuniform bristle configurations over the circumference in both the OD and ID brushes. However, although the circumferential pressure distributions varied significantly, there was no distinct evidence that the sharp changes in local pressure affected the bristle configurations. Various sections of the brush seals having nearly the same porosities had very different unpacked arrays. These differences would cause large variations in modeling and subsequent fluid dynamics computations and may account for the departures from idealized flow predicted by the Ergun relations and experimental data.

No sacrificial metallurgical examinations were undertaken, but the bristles did wear-in on the rotor. The optical microscope revealed bristle tip grooving, and material transfer could be inferred from the cast-iron-fracture-like appearance of the OD brush bristle tips. ID brush bristle tips were similar except that no grooving was evident. The coated rotor appeared to have been polished without distress, except for "car track" scars and marks from bristle whipping or bristle bunch incursion loading. These marks may be related to residual tooling or surface hardening in the parent rotor material. The car track scars, or inner and outer wear bands, may result from bristle stiffening at the fence plate during one portion of the rotor cycle and stiffening at the gap plate during other portions of the rotor cycle. Small pressure perturbations may cause bristle flutter during the lightly loaded portion of the cycle. These results support the assumption that the bristle wear patterns directly reflect the pressure loading at the blade passing frequency.

Although the test time and operating conditions were limited, the rotor surface appeared to be polished, the bristles did wear-in, and the brush seals provided enhanced component efficiencies over the baseline.

\section{References}

Athavale, M.M. et al. (1995) "An integrated fluid-structure and heat transfer analysis methodology for brush seals," SBIR Phase I Final Report, NAS3-27530, CFD Research Corp., Huntsville, AL.

Bird, R.B., Stewart, W.E. and Lightfoot, E.N. (1960) Transport Phenomena, John Wiley, New York. 
Braun, M.J., Canacci, V.A. and Hendricks, R.C. (1990) "Flow visualization in a simulated brush seal," Paper 90-GT-217, 35th International Gas Turbine and Aeroengine Congress and Exposition, ASME, Fairfield, NJ.

Carlile, J.A., Hendricks, R.C. and Yoder, D.A (1992) “Brush seal leakage performance with gaseous working fluids at static and low rotor speed conditions," Paper 92-GT-304, 37th International Gas Turbine and Aeroengine Congress and Exposition, ASME, Fairfield, NJ.

Ergun, S. (1952) "Fluid flow through packed columns," Chemical Engineering Progress, 48(2), 89-94.

Hendricks, R.C., Braun, M.J., Canacci, V.A. and Mullen, R.L. (1990) "Brush seals in vehicle tribology" Proceedings of the 13th Leeds-Lyon Symposium on Tribology, Leeds, England.

Hendricks, R.C., Carlile, J.A. and Liang, A.D. (1992) "Some sealing concepts - A review, Part A: industrial, proposed, and dynamic," ISROMAC-4, Fourth International Symposium on
Transport Phenomena and Dynamics of Rotating Machinery Begell House, New York, Vol. A, pp. 204-221.

Hendricks, R.C., Wu, T., Wilson, J. and Flower, R. (1997) "Bidirectional brush seals," Paper 97-GT-256, 42nd International Gas Turbine and Aeroengine Congress and Exposition, ASME, Fairfield, NJ. (Also NASA TM-107351.)

Kentfield, J.A.C. (1995) "On the Feasibility of gas-turbine pressure-gain combustors," International Journal of Turbo and Jet Engines, 12(1), 29-36.

Kudriavtsev, V.V., Hendricks, R.C. and Braun, M.J. (1997) Pressure drop design curves for the brush seal applications, Joint Propulsion Conference Seattle, WA, AIAA-97-2635.

Wilson, J. (1997) "An experiment on losses in a 3-port wave rotor," NASA CR-198508.

Wilson, J. and Paxson, D.E. (1996) "Wave rotor optimization for gas turbine engine topping cycles," Journal of Propulsion and Power, 12(4), 778-785. 


\section{ait \\ ENERGY MATERIALS}

M A N E Y publishing

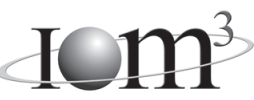

\section{Materials Science \& Engineering for Energy Systems}

Maney Publishing on behalf of the Institute of Materials, Minerals and Mining

The Institute of Materials, Minerals \& Mining

Economic and environmental factors are creating ever greater pressures for the efficient generation, transmission and use of energy. Materials developments are crucial to progress in all these areas: to innovation in design; to extending lifetime and maintenance intervals; and to successful operation in more demanding environments. Drawing together the broad community with interests in these areas, Energy Materials addresses materials needs in future energy generation, transmission, utilisation, conservation and storage. The journal covers thermal generation and gas turbines; renewable power (wind, wave, tidal, hydro, solar and geothermal); fuel cells (low and high temperature); materials issues relevant to biomass and biotechnology; nuclear power generation (fission and fusion); hydrogen generation and storage in the context of the 'hydrogen economy'; and the transmission and storage of the energy produced.

As well as publishing high-quality peer-reviewed research, Energy Materials promotes discussion of issues common to all sectors, through commissioned reviews and commentaries. The journal includes coverage of energy economics and policy, and broader social issues, since the political and legislative context influence research and investment decisions.

\section{CALL FOR PAPERS}

Contributions to the journal should be submitted online at http://ema.edmgr.com

To view the Notes for Contributors please visit: www.maney.co.uk/journals/notes/ema

Upon publication in 2006, this journal will be available via the Ingenta Connect journals service. To view free sample content online visit: www.ingentaconnect.com/content/maney

For further information please contact:

Maney Publishing UK

Tel: +44 (0)113 2497481 Fax: +44 (0)1132486983 Email: subscriptions@maney.co.uk

or

Maney Publishing North America

Tel (toll free): 8662975154 Fax: 6173546875 Email: maney@maneyusa.com

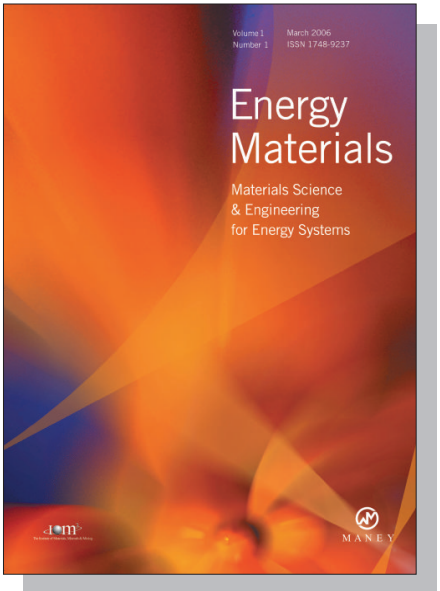

EDITORS

Dr Fujio Abe

NIMS, Japan

Dr John Hald, IPL-MPT, Technical University of Denmark, Denmark

Dr R Viswanathan, EPRI, USA

\section{SUBSCRIPTION INFORMATION}

Volume 1 (2006), 4 issues per year

Print ISSN: 1748-9237 Online ISSN: 1748-9245

Individual rate: $£ 76.00 / U S \$ 141.00$

Institutional rate: $£ 235.00 /$ US $\$ 435.00$

Online-only institutional rate: $£ 199.00 / U S \$ 367.00$

For special $\mathrm{IOM}^{3}$ member rates please email

subscriptions@maney.co.uk

\section{For further information or to subscribe online please visit www.maney.co.uk}



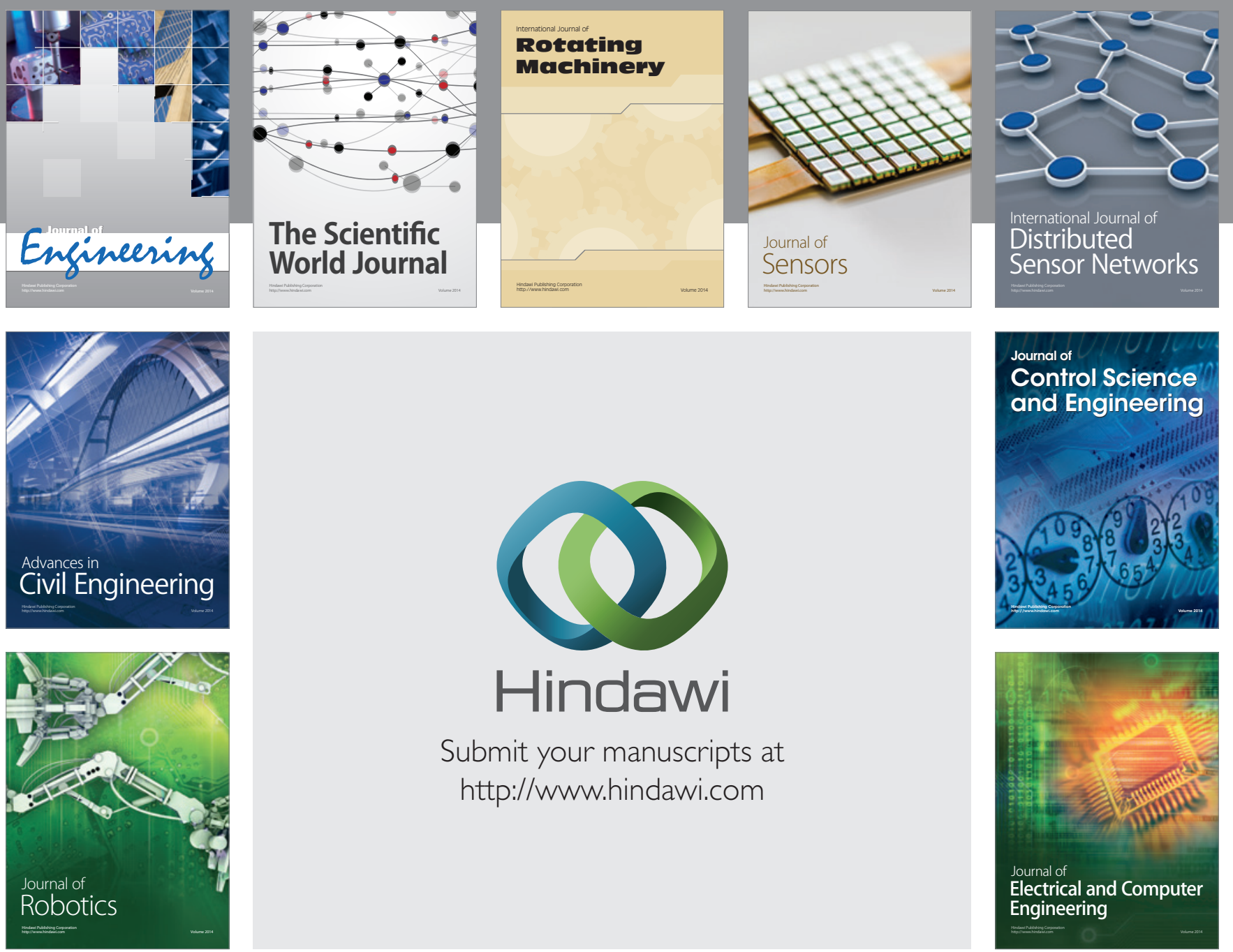

Submit your manuscripts at

http://www.hindawi.com
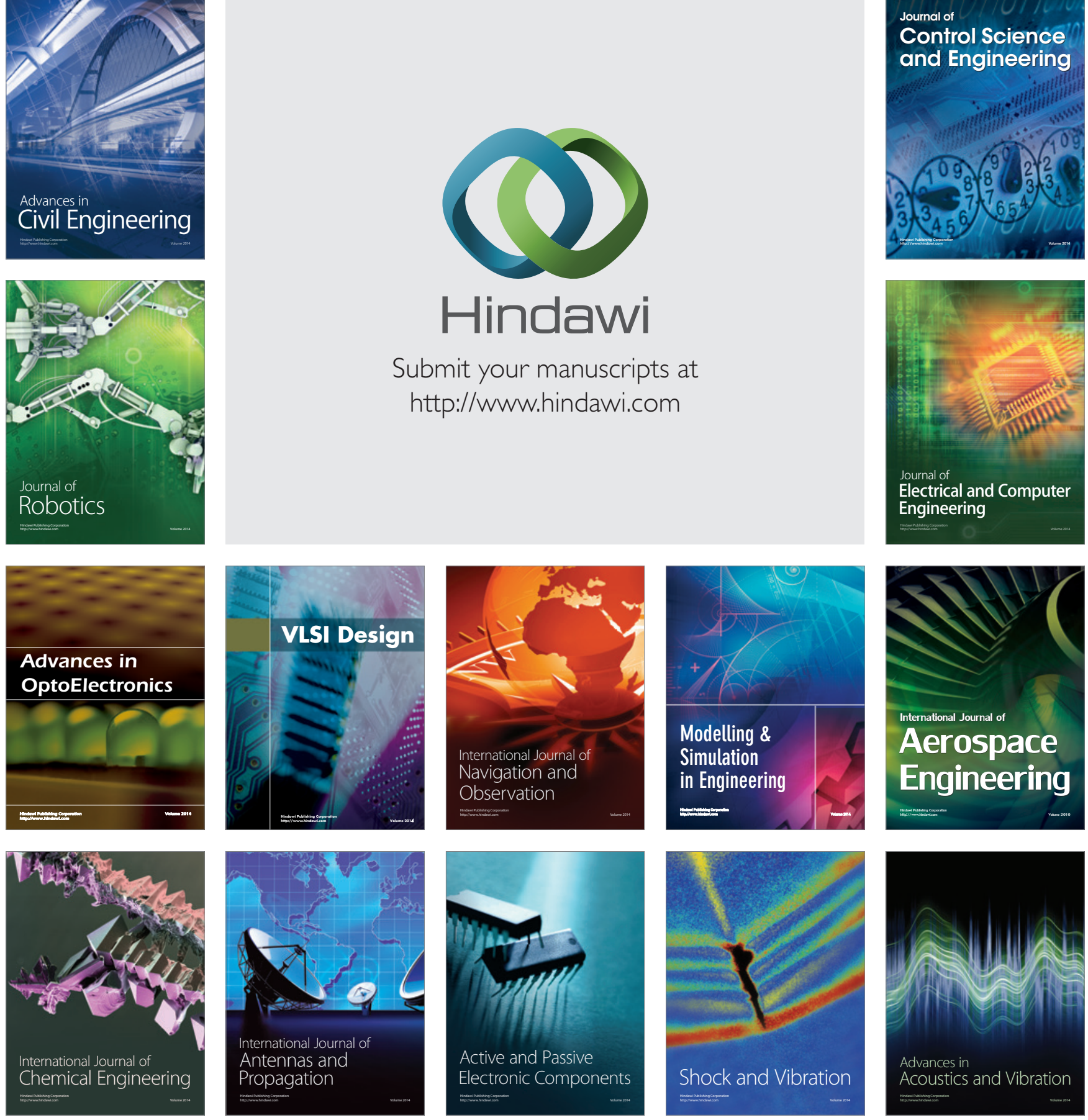